\title{
The Significance and Implementation Strategy of Introducing Football Teaching into the Classroom
}

\author{
Qiu Feng \\ Teaching and Research Section of Physical Education, Heyuan Polytechnic, Guangzhou, 517000, \\ China
}

Keywords: flipping classroom, elementary school, Football teaching model

\begin{abstract}
: with the development of the education of information technology, traditional football sports teaching mode cannot meet the needs of teachers and students, in many of the new teaching mode, the "flip" class the teaching mode gradually penetrate into the primary school football sports classroom teaching, improve the students' learning interest, better skills mastered all kinds of sports, promote the students themselves and improve autonomous learning ability, make students willing to participate in football exercise, better improve students' physical and mental health. Let the student establish the innovation, the independence, the happy soccer sports consciousness from the childhood, lets the soccer sports technical skill thorough arrive in the student's heart, lets the student fall in love with the soccer sports, lets the study have the significance.
\end{abstract}

\section{Introduction}

With the development of the information age, especially the infiltration and influence of Internet + on teaching, as well as the needs of teachers, students and all sectors of society for educational Informatization, the traditional teaching mode of football physical education, which focuses on "teacher-student learning", has been unable to meet the needs of all aspects. The traditional football physical education teaching process is mainly the teacher demonstration teaching, the student drills mechanically, cannot give full play to the student's study independence, the teaching efficiency is low. However, after the application of the new teaching mode of flipped classroom, the teaching subject is changed from teacher to student. With the help of micro video and learning task list, students internalize the classroom learning action in advance to the class, so that students can more intuitively and happily accept knowledge and master skills, and make the classroom more effective and efficient.

\section{Research background}

According to the 13th five-year plan of the ministry of education teachers are encouraged to use information technology to carry out activities such as lesson preparation, home-school interaction, network research and study, and guiding students' learning. Students are encouraged to use information technology to carry out learning activities such as preview, homework, self-test, extended reading and online elective courses, and develop good habits of self-management, 
self-learning and self-service. Encourage parents to use the Internet to communicate and interact with schools and teachers conveniently, pay attention to students' learning and growth process, and effectively guide students to use space scientifically. It is necessary to realize the network learning space presentation of students' learning process and practical experience record. Relying on the network learning space, it gradually realizes the big data collection and analysis of students' daily learning situation, and optimizes the teaching mode, so as to further reflect the comprehensive efficiency of "school-school communication" and "class communication" through the extensive and in-depth application of "everyone communication".

Based on the deep integration of information technology and education, it is required to establish a new teaching environment, optimize education mode and promote education reform. The core of the new curriculum reform is "student-oriented", based on changing the current education and teaching situation, advocating the "independent, collaborative, inquiry" learning method, paying attention to the positive learning attitude, creating a new type of classroom teaching activities, in order to seek the comprehensive development of students. As a new teaching mode, "flipped classroom" has obtained new research and development under the current information education background, which has a significant impact on China's education and teaching reform. This study to flip the classroom teaching process as a research starting point, based on the theory of teaching theory, the analysis of features of flip the classroom teaching process, design analysis, to flip video and classroom task list as the research object, focus on the effectiveness of learning, pay attention to students' learning motivation, interest and active participation, etc. The full use of flipped classroom teaching mode in football sports teaching can improve students' interest in learning, enhance their learning initiative, make students intuitively and happily accept knowledge and master skills, and make the class more effective and efficient.

\section{Research methods}

- Field research method: Conduct on-the-spot investigation and research on the implementation of the application of primary school flip classroom in Football teaching, and analyse the advantages of the classroom.

- Documentary Law: Review a large number of related materials, including papers, documents, books and periodicals.

- Interview method: The survey interviewed Football teaching teachers and students to understand their views and suggestions on the application of flip classroom in Football teaching.

- Data statistics method: Questionnaire survey on the learning effect of flipping classrooms. After the validity and reliability test of the collected questionnaires, use excel software for processing and statistical analysis.

- Observation method: Through the in-depth and meticulous observation of the flipping classroom, the angle analysis analyses the formation factors of the classroom.

\section{The research results and analysis}

\subsection{The concept of flipping the classroom}

"Flip the classroom" is defined as "reverse classroom" or "reverse classroom". It is a new type of teaching mode, which is to carry out knowledge transfer through information technology, and then internalize knowledge through face-to-face teaching and teacher-student information interaction platform. 
Table 1 Student physical exercise frequency table after the introduction of teaching in the flip classroom $(\mathrm{N}=200)$

\begin{tabular}{lllllll}
\hline $\begin{array}{l}\text { Movement frequency } \\
\text { (times/week) }\end{array}$ & $\mathbf{0}$ & $\mathbf{1}$ & $\mathbf{2}$ & $\mathbf{3}$ & $\mathbf{3}$ & $\mathbf{X}^{\mathbf{2}}$ \\
\hline $\begin{array}{l}\text { Number of people } \\
\text { Percentage (\%) }\end{array}$ & 8 & 99 & 43 & 40 & 10 & 61.598 \\
\hline
\end{tabular}

As shown in the above table, in the "flip classroom" Football teaching carried out by the author, the teacher made micro-video upload to two frog platforms and arranged learning tasks. Students can arrange learning according to their own situation and conduct discussion and discussion in the classroom. In the middle, the teacher will guide according to the students' learning situation and exchange of discussions.

\subsection{Investigation and analysis of the application status of flipping classroom in Football teaching}

Through interviews with students and their parents, it is learned that students do not have enough knowledge and attention to the use of flipping classrooms in sports. Most students are confused about the application forms and processes of flipping classrooms in Football teaching, due to traditional teaching. The concept of teaching and teaching mode, most parents tend to focus on the traditional Football teaching mode. China's current Football teaching also follows the educational thought and teaching mode of the former Soviet educator Kailua, which is formed from the law of understanding.

Table 2 The best time for the Football teaching under the classroom $(\mathrm{N}=200)$

\begin{tabular}{lllll}
\hline Exercise time (min) & $<\mathbf{3 0}$ & $\mathbf{3 0 - 6 0}$ & $>\mathbf{6 0}$ & $\mathbf{X}^{\mathbf{2}}$ \\
\hline Number of people & 106 & 58 & 36 & 77.541 \\
Percentage (\%) & 55.1 & 29.2 & 15.7 & \\
\hline
\end{tabular}

As shown in Table 2 above, in the traditional teaching process, the teacher first demonstrates and explains the essentials of the action, then the teaching, the students imitate the practice, the teacher then guides from the side, and finally the review and consolidation, this teaching method is more suitable for the student group. With the deepening of learning, in the teaching, it is difficult for teachers to take into account the learning situation of each student. The Football teaching links are interlocking. When some students encounter some difficult actions, they cannot get timely corrections. Guidance, the next link cannot keep up with the progress, so that the study of sports technology is caught in a vicious circle; while some students master the skills quickly, and hope to enter the next action link as soon as possible, this teaching method will cause students to eat and eat enough Not full. Secondly, due to the simplification of its teaching content and methods, students are gradually losing interest in Football teaching. Therefore, the teaching of sports urgently needs a new teaching method to improve the current status of Football teaching. At this time, flipping the classroom form solved the problem to some extent.

\subsection{Application Strategy of "Flipping Classroom” in Football teaching}

\subsubsection{Conversion learning method}

Teachers should make full use of the advantages of modern education and turn information technology into an assistant to classroom teaching. Before the classroom teaching, students should 
independently explore the mastery of action technology by watching micro-videos and learning task lists, through learning objectives and micro-video explanations. For example, in the teaching of obstacle running, students are allowed to freely combine exercises before class, and the essentials of the movements that cannot be mastered are controlled, analysed, improved, and communicated with teachers and students on the interactive platform. More intuitive and effective grasp of each action detail of the swing.

\subsubsection{Transforming the learning role}

In order to fully cultivate students' interest in learning, enhance students' initiative and enthusiasm, change the "audience" into "actor", and let the "supporting role" become the "protagonist". Teachers should change their role orientation and extend from in-class practice to extracurricular activities. For example, when teaching at the level of obstacles, I try to arrange self-study tasks before class, let the students go home and watch the micro-videos with their parents, and communicate with them on the Internet to let students explore some learning methods independently. In the classroom, students put How to master the essential methods for display, through the questions and answers between teachers and students, one cooperation and one comment, thus transforming the teaching of single teacher-led into the inquiry-based teaching with students as the main body, effectively improving the teaching effect.

\subsubsection{Transforming teaching methods and learning methods}

The traditional teaching is in the classroom, the teacher demonstrates, the students practice, and the current classroom is the micro-video and micro-courses that the teachers carefully design through the technical movements, so that the students can learn independently at home, and discuss the difficulties and difficulties in the interactive platform and the teacher. Self-learning has solved the situation of listening more and less in the classroom, effectively improving the students' understanding of the deep understanding of the surface of the movement, allowing the students to more deeply understand and master the movements, and the teacher can In the classroom, you don't have to spend more time to explain the demonstration, focus on the lack of vacancies, answer questions, and consolidate and improve. Students can also consolidate and enhance their technical actions in the atmosphere of independent inquiry and group cooperation.

\section{Problems that arise when applying the "Flip Classroom" teaching mode}

"Flip classroom" is a new teaching model that has not been widely used in most classroom teaching, so it does not have a solid foundation. Therefore, teachers may not be able to update their ideas in the process of teaching, or they are strongly excluded because of their habits. On the other hand, it may be because this teaching mode can reduce the teaching burden for teachers, and it is effective, so it will from the auxiliary tools of teaching to the leading tools, using teaching videos and ignoring personal explanations and actual teaching, teachers lose their guiding role in their teaching process. Based on this, we jointly developed specific experimental plans and procedures. And use the card square test formula to analyse the results of the reform attempt:

$$
x^{2}=\sum \frac{\left(f_{0}-f_{e}\right)^{2}}{f_{e}} \sim \chi^{2}
$$

This is the original formula of the chi-square test, where the greater the $f_{e}\left(f_{e} \geq 5\right)$, the better the approximation. Obviously the greater the difference between $f_{o}$ and $f_{e}$, the larger the chi-squared value; the smaller the difference between $\mathrm{f}_{\mathrm{o}}$ and $\mathrm{f}_{\mathrm{e}}$, the smaller the chi-squared value; hence it can 
be used to represent the degree of difference between $f_{o}$ and $f_{e}$.

In addition, because the teacher will do a lot of video recording and data preparation before the class, the teacher may be lazy, let the "flip classroom" only flow into the form, and become an empty classroom. At the same time, when students use the platform to learn and communicate, they may also be addicted to the game. The students' learning is in an unsupervised state and the learning efficiency is low.

\section{Conclusions}

The flipped classroom teaching mode in football sports teaching not only exercises students' independent learning ability and changes the learning form, but also improves the space of communication and interaction between teachers and students, effectively promoting the healthy and happy growth of students. Strong trend along with the development of the society Informatization, football sports teaching reform is imperative, through the introduction of the concept and function of flip classroom teaching mode, to the present stage of football sports teaching present situation has carried on the simple analysis, and has carried on the attempt and summary, positive gradually realized that the subject role of students in football sports teaching, especially the flip the transformation of classroom teaching, students are more likely to play initiative of learning, learning to be your own thing and become a drive to promote growth, but in practice, it is some problem, need positive exploration practice, strengthen learning, strive to solve the problem of classroom teaching, Make the flipped classroom teaching form more close to and suitable for students to learn.

\section{References}

[1] Shannon M E. School-based childhood obesity prevention targeting middle schools: A grant proposal[J]. Dissertations \& Theses - Gradworks, 2015.

[2] Casey A, Dyson B. The implementation of models-based practice in Football teaching through action research.[J]. European Football teaching Review, 2016, 15(2):175-199.

[3] Lu C, School Z M, Nantong. Implementation Strategy of Practicing Moral Construction and Student Cultivation Concept in Middle School Football teaching[J]. Bulletin of Sport Science \& Technology, 2018. 